\title{
Seasonal Change in Diet and Habitat Use in Wild Mandrills (Mandrillus sphinx)
}

\section{$\operatorname{AUTHOR}(\mathrm{S})$ :}

Hongo, Shun; Nakashima, Yoshihiro; AkomoOkoue, Etienne François; Mindonga-Nguelet, Fred Loïque

\section{CITATION:}

Hongo, Shun ...[et al]. Seasonal Change in Diet and Habitat Use in Wild Mandrills (Mandrillus sphinx). International Journal of Primatology 2018, 39(1): 27-48

\section{ISSUE DATE:}

2018-02

URL:

http://hdl.handle.net/2433/230380

\section{RIGHT:}

This is a post-peer-review, pre-copyedit version of an article published in 'International Journal of Primatology'. The final authenticated version is available online at: https://doi.org/10.1007/s10764-017-0007-5.; The full-text file will be made open to the public on 1 February 2019 in accordance with publisher's 'Terms and Conditions for Self-Archiving'; This is not the published version. Please cite only the published version. この論文は出版社版でありません。引用の際 には出版社版をご確認ご利用ください。 
1 Seasonal Change in Diet and Habitat Use in Wild

2 Mandrills (Mandrillus sphinx)

3

4 Shun Hongo, Yoshihiro Nakashima, Etienne François

5 Akomo-Okoue, and Fred Loïque Mindonga-Nguelet

6

7 International Journal of Primatology

8 Vol. 39, Issue 1 (February 2018). pp. 27-48.

9

10 DOI: $10.1007 / \mathrm{s} 10764-017-0007-5$

13 The final publication is available at link.springer.com. 
Seasonal Change in Diet and Habitat Use in Wild Mandrills (Mandrillus sphinx)

16 Short running title: Diet and Habitat Use in Mandrills

17 Shun Hongo ${ }^{1,5,6}$, Yoshihiro Nakashima ${ }^{2,5,6}$, Etienne François Akomo-Okoue ${ }^{3,6}$, Fred Loïque

18 Mindonga-Nguelet ${ }^{3,4,6}$

19

Authors' institutional affiliations:

1. Section of Ecology and Conservation, Primate Research Institute, Kyoto University

2. College of Bioresource Science, Nihon University

3. Institut de Recherche en Écologie Tropicale, Centre National de la Recherche Scientifique et Technologique (IRET, CENAREST)

4. Faculté des Sciences, Université des Sciences et Techniques de Masuku

5. Department of Zoology, Graduate School of Science, Kyoto University

6. Project for Conservation of Biodiversity in Tropical Forest through Sustainable Coexistence between Human and Wild Animals (PROCOBHA)

Author for correspondence

Shun Hongo

Section of Ecology and Conservation, Primate Research Institute, Kyoto University

41-2, Kanrin, Inuyama-shi, Aichi, 484-8506, Japan

E-mail: hongo.shun.8s@kyoto-u.ac.jp 


\section{Abstract}

Primates show various behavioural responses to resource seasonality, including changes in diet and habitat use. These responses may be particularly important for species living in large groups, due to strong competition for resources. We investigated seasonality in diet and habitat use in wild mandrills (Mandrillus sphinx), which form some of the largest primate groups, in Moukalaba-Doudou National Park, Gabon. We used a fallen fruit census to measure fruit availability and camera-trapping to measure visit frequency by mandrill groups on 11 line transects from January 2012 to November 2013, and collected mandrill faeces for 25 months in 2009-2013 to assess their diets. Fruit availability varied seasonally, with a peak in December-February, and a scarce period in March-August. Relative volumes of fruit skin, pulp and intact seeds in faecal remains varied with fruit availability, whereas faeces contained as a large proportion of crushed seeds in the fruit scarce season as in the fruit-peak season. The relative volumes of woody tissue (e.g., bark and roots) and the number of food types increased in the fruit-scarce season compared to in the fruit-peak season. Camera-trapping revealed seasonality in habitat use. In fruit-rich seasons, mandrill visits were highly biased towards transects where fruit species that appeared in the majority of faeces in a group were abundant. In contrast, in fruit-scarce seasons, visit frequencies were distributed more uniformly and the relationship with fruit availability was unclear. Our results suggest that mandrill groups in the study area respond to seasonal fruit scarcity by consuming seeds and woody tissue and by ranging more widely than in fruit-rich seasons. These flexible dietary and ranging behaviours may contribute to the maintenance of extremely large groups in mandrills.

62 Keywords: Behavioural flexibility; Camera-trapping; Faecal analysis; Fruiting phenology; 63 Moukalaba-Doudou 
65

66

67

68

69

\section{Introduction}

Primates show a wide variety of diets and habitat use patterns between and within species.

While body size and morphology largely determine primate diet and habitat use (Fleagle 2013), social organisation and environmental factors, including disturbance (Johns and Skorupa 1987), seasonal inundation (Terada et al. 2015) and topographic steepness (Etiendem et al. 2013), also affect habitat use patterns. Since food resources change seasonally in most of the primate habitats (Hanya et al. 2013; van Schaik and Pfannes 2005), behavioural responses to resource seasonality, including changes in diet and habitat use, are important adaptations for most primates (Hemingway and Bynum 2005; Tsuji et al. 2013). For example, rhesus macaques (Macaca mulatta) eat more mature leaves (Tang et al. 2016) and eastern lowland gorillas (Gorilla beringei) eat more bark and leaves (Yamagiwa et al. 1994) when fruits become scarce. Larger species except great apes $(5-15 \mathrm{~kg})$ tend to eat lower-quality foods, such as mature leaves and other vegetative matter, than smaller species, which rely on higherquality exudate and nectar for alternative foods during fruit scarce seasons (Hemingway and Bynum 2005). Some primates show seasonal differences in dietary diversity. For example, Japanese macaques (Macaca fuscata: Nakagawa 1989) and black-and-white colobus (Colobus guereza: Harris et al. 2010) have more diverse diets in seasons where their main foods are scarce, whereas blue monkeys (Cercopithecus mitis: Kaplin et al. 1998) decrease dietary diversity by eating a particular seed species frequently when fruits are scarce. Dietary responses can also vary between populations of the same species (e.g., grey-cheeked mangabeys, Lophocebus albigena: Hemingway and Bynum 2005). Changes in ranging patterns include seasonal changes in habitat (e.g., common brown lemurs, Eulemur fulvus: Sato 2013) and increased home range size (e.g., tufted capuchins, Sapajus apella: Di Bitetti 2001).

Biogeographic differences in phenology and environments affect primate 
90 behavioural responses to food seasonality (Hemingway and Bynum 2005). For example, while

91 African primates often show increased dietary diversity during seasons of food scarcity but do not change in home range size seasonally, New World monkeys, particularly Atelinae and Cebinae species with relatively large home ranges, rarely increase diversity of their diets but often expand their home range or change their habitats when foods are scarce. These regional contrasts may be due to differences in phenology and forest structure: the interval between peak leaf flush and peak fruiting is shorter in American than in African forests (van Schaik and Pfannes 2005), and the Amazonian waterways cause high heterogeneity of habitat types in American tropical forests (Hemingway and Bynum 2005).

Group size may also influence primate seasonal behaviours, and behavioural

100 responses may be particularly important for large groups, since larger groups experience

101 stronger scramble feeding competition (Janson 1988). For example, the dietary diversity of

102 red colobus (Procolobus rufomitratus) correlates positively with their group size (Gogarten et al. 2014), and seasonal changes in habitat are confined to species with the largest group sizes among the primate community at Uruku River, Brazil (Peres 1994). forests in central Africa where resource production varies seasonally (Newbery et al. 1998;

107 White 1994). They form among the largest wild primate groups of up to 845 (mandrills: Abernethy et al. 2002) and 400 (drills: Wild et al. 2005) individuals. However, the dense

109 vegetation of their habitats make it difficult to observe them directly without habituation,

110 which is nearly impossible due to their large group sizes and large home ranges. Consequently,

111 no ecological studies of mandrills or drills based on direct behavioural observations of 112 identified animals have been achieved in the wild, and available data are limited to a 113 provisioned mandrill group established by releasing captive animals in Lékédi Park, Gabon 114 (Brockmeyer et al. 2015; Nsi Akoue et al. 2017). 
Based on indirect data from faeces and food remnants, wild mandrills and drills are omnivorous with a high preference for fruits (Astaras and Waltert 2010; Hoshino 1985; Lahm 1986; Rogers et al. 1996). Provisioned mandrills are also omnivorous with a clear frugivorous tendency (Nsi Akoue et al. 2017). Mandrillus species, and closely-related Cercocebus species, have enlarged premolars, which are adapted to processing hard nuts and seeds (Fleagle and McGraw 2002), and monkeys of both genera eat seeds frequently (Astaras and Waltert 2010; Hoshino 1985; McGrew et al. 2009). However, seasonal patterns in diets differ between the genera: while Mandrillus species increase the diversity of food types by eating fallen seeds and monocotyledonous herbs in fruit-scarce seasons (Astaras and Waltert 2010; Hoshino 1985; Tutin et al. 1997), Cercocebus species eat a lot of fruits and seeds year-round, and changes in their diet do not always relate to fruiting seasonality (McGraw et al. 2014; Mitani 1989).

We know much less about ranging behaviours of wild mandrills and drills than about their diets. A study in Lopé National Park, Gabon, estimated the home range of a wild mandrill group of $c a .700$ individuals at $182 \mathrm{~km}^{2}$, including $89 \mathrm{~km}^{2}$ of forested area (White et al. 2010), whereas a provisioned mandrill group of 120 animals has much smaller home range of $8.7 \mathrm{~km}^{2}$ (Brockmeyer et al. 2015). Surveys report that mandrills prefer primary forests and avoid savannah (Lahm 1986; Rogers et al. 1996), and drills occur from lowland to montane forests at up to 2,000 m elevation (Wild et al. 2005). Their seasonality in habitat use is barely understood. Researchers at Lopé (Rogers et al. 1996) observed groups in gallery forests more

135 frequently during dry seasons than rainy seasons, but a subsequent report at the same site

136 (White 2007) did not confirm this pattern because the core area of the group was in gallery

137 forests regardless of season. Conversely, Cercocebus mangabeys mainly inhabit riverine and 138 swamp forests with groups of 10-125 animals and much smaller home ranges of 1-3 $\mathrm{km}^{2}$

139 (Swedell 2011), and red-capped mangabeys (C. torquatus) show seasonal changes in habitat 
140 (Mitani 1989).

141 In this study, we examined seasonal changes in the diet and habitat use of wild 142 mandrills in Moukalaba-Doudou National Park, Gabon. A previous study at the same site

143 (Hongo 2014) obtained three full counts of mandrill groups of 169, 350 and 442 individuals,

144 but we do not know how many groups there are in our study population. We obtained data on 145 diet from faecal samples, and used camera-traps to collect data on differential habitat use, both 146 for multiple unhabituated groups. Digestive efficiencies vary with food type (Litvaitis 2000), 147 so we used faecal analysis to examine seasonal differences in the consumption of each food 148 type, but did not compare the relative importance of food types.

149 We had three objectives. First, we assessed fruiting phenology in the study area to 150 define seasons based on fruit availability. Second, we examined seasonal changes in mandrill 151 diet by comparing the relative volumes of each food type and the number of food types in 152 faecal remains between seasons. Third, we examined seasonal changes in mandrill habitat use based on the frequency of visits to camera-traps. We explored correlations between visit frequency and the availability of important mandrill fruits, seasons, and habitat parameters, and compared the spatial distribution of visits to camera traps between seasons to explore seasonality in mandrill ranging patterns.

\section{Methods}

\section{Study Area}

160 Our study area encompassed about $400 \mathrm{~km}^{2}$ in the eastern part of Moukalaba-Doudou National

161 Park, Gabon. Given that a home range of the mandrill group at Lopé includes $89 \mathrm{~km}^{2}$ of 162 forested area (White et al. 2010), the study area is likely to cover the home ranges of several 163 groups. Our base camp was located at $\mathrm{S} 2^{\circ} 19^{\prime}$ and $\mathrm{E} 10^{\circ} 34^{\prime}$. The study area comprises different 164 habitat types, according to Landsat ${ }^{\mathrm{TM}}$, radar and aerial imagery (Ministère des Eaux et Forêts 
et du Reboisement, Tecsult International, Quebec, Canada; provided by WWF Gamba; Fig. 1).

166 Annual rainfall during 2002-2013 was 1,176-2,043 mm, and the mean monthly minimum and maximum temperatures during $2006-2013$ were $18.7-25.0^{\circ} \mathrm{C}$ and $26.7-34.3^{\circ} \mathrm{C}$, respectively (PROCOBHA research team, unpublished data). Typically, the dry season is from May to September, and the rainy season is from October to April, but there is little rain from December to February in some years (Takenoshita et al. 2008).

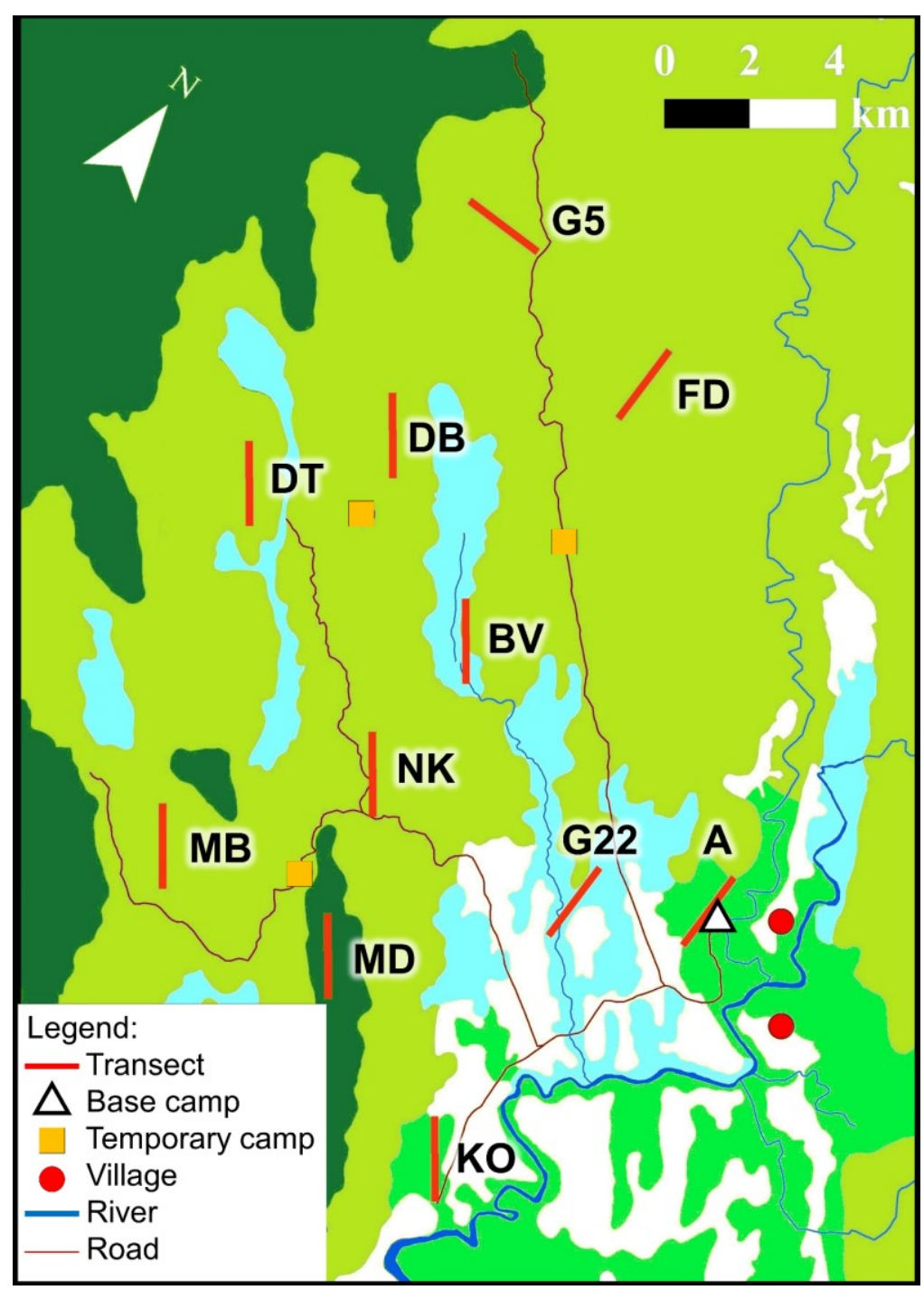

173 Fig. 1 Map of the study area in Moukalaba-Doudou National Park, Gabon, with transects and 174 vegetation types. Dark green (transect MD) is mountainous primary forest; olive green (NK, 
$175 \mathrm{MB}, \mathrm{DB}, \mathrm{DT}, \mathrm{FD}$, and G5) is lowland primary forest; lime green (A and $\mathrm{KO}$ ) is disturbed

176 secondary forest; light blue (G22 and BV) is seasonally inundated riverine forest; white is savannah.

\section{Fruiting Phenology and Definition of Seasons}

180 To monitor fruiting phenology in the study area, we conducted a monthly fallen-fruit census

181 (Furuichi et al. 2001) from January 2012 to January 2014. We established 11 line transects 182 separated by at least $2 \mathrm{~km}$ and covering all types of vegetation in the study area (Fig. 1). We

183 set the length of transects to $2 \mathrm{~km}$ to prevent transects from crossing different vegetation types.

184 We defined a 'fruit cluster' as one or more fresh fruits that had fallen on the ground from the

185 same tree. We noted and photographed fruit clusters of all species within $1 \mathrm{~m}$ of the centre of 186 the transects (total area censused $=4.4$ ha). We also counted partially-eaten fruits as fruit 187 clusters if we found a fruiting tree of the same species above them. To avoid counting multiple clusters from the same fruiting tree, we did not record clusters that fell within $10 \mathrm{~m}$ of the previous cluster of the same species. When we found two fruit clusters of the same species more than $10 \mathrm{~m}$ apart, we only counted the second cluster if we found a different fruiting tree above them. Thus, the number of fruit clusters should match the number of fruiting trees near the transects, although we may have failed to count tree species whose fruits seldom fall to the ground or rarely remain for a long time due to consumption by animals (Furuichi et al. 2001).

Our measure is a rough indicator of fruit abundance as we did not quantify the numbers or the mass of the fruits.

We attempted to classify the fruit clusters taxonomically using photographs and plant

197 lists for our study area (Takenoshita et al. 2007; Yumoto et al. 2015). We finished the 198 classification of the fruits found in mandrill faeces; the classification of other fruit species is 199 ongoing. 
examine seasonal variation in fruit availability, we drew boxplots of the monthly numbers of

fruit clusters of all species, based on which we defined four seasons: 'fruit-peak season' from

December to February, 'early fruit-scarce season' from March to May, 'late fruit-scarce season'

whether numbers of fruit clusters are statistically different among the four seasons using pairwise Welch t-tests with the Holm's p-value adjustment (Holm 1979).

\section{Faecal Sample Collection and Analysis}

209 We searched for mandrill groups with research assistants over the whole study area for 25 210 months between 2009 and 2013 (August-November 2009, January-June 2010, November

211 2011-March 2012, June-August 2012, October 2012-February 2013, and June-September

212 2013). When we found a group, we followed it and collected faecal samples ad libitum.

We conducted faecal analysis following a standardised protocol (McGrew et al. 2009). On the day of collection, we washed faecal samples in a $1-\mathrm{mm}^{2}$ sieve until the waste water was clear and dried the samples in the shade. We then sorted faecal remains into nine food types using a magnifying glass: fruit fibre (fruit skin, pulp, and intact seeds); crushed seeds (including crushed seed coats); dicotyledonous leaves; monocotyledonous herbs (blades and pith); woody tissue (bark, woody liana, roots and subterranean stems); flowers; invertebrates; vertebrates (hairs and feathers); and other (including soil, stones, and dead leaves). Unlike several previous studies of Mandrillus species, where intact seeds were discarded and/or fruit fibre and seeds were both categorised as 'fruits' (Hoshino 1985; Owens et al. 2015), we categorised intact and crushed seeds into 'fruit fibre' and 'seeds', respectively, because fruit fibre and seeds are considerably different in terms of phenology and nutrition intake. Since fruit skin and pulp rarely occurred in faeces, and the occurrence of intact seeds 
means that mandrills receive nutrition from fruit skin and/or pulp not from seeds, excluding intact seeds would substantially underestimate the dietary contribution of fruit fibre. We estimated the relative volume of each food type in the faecal remains on a five-point scale at $25 \%$ intervals (i.e., $0 \%, 12.5 \%, 37.5 \%, 62.5 \%$, and $87.5 \%$ ).

We identified fruit items to the lowest possible taxonomic group based on their morphological traits. We identified 'important' fruits for mandrills from the list of fruit items found in their faeces. To find an objective threshold for importance, we calculated proportion of occurrence by date and fruit item whenever we collected more than five faeces during a group follow, and plotted a density curve. The curve showed a bimodal distribution with a local minimum at $61.7 \%$. We therefore defined important fruits as fruit items that occurred $\geq$ $60 \%$ at least once.

\section{Camera-trapping and Capture Rate of Mandrill Groups}

From January 2012 to February 2014, we deployed 10 camera-traps (Bushnell® Trophy Cam 2010, Overland Park, MO) along each transect at 200-m intervals, as part of a comprehensive study of mammalian ecology (Nakashima 2015). We strapped each camera to a tree $10 \mathrm{~m}$ from the transect and adjusted it to be parallel to the ground at a height of $30 \mathrm{~cm}$. We did not move cameras during the study period. We configured the cameras to start in response to the passage of animals and to record a video image of $30 \mathrm{~s}$ or $60 \mathrm{~s}$ at a minimum interval of $30 \mathrm{~s}$ ( $3 \mathrm{~min}$ from January to July 2012). We checked the conditions of the cameras monthly and replaced them as soon as possible when they broke.

We used camera-trap data from January 2012 to November 2013 for analysis, because the number of deployed camera-traps decreased substantially in December 2013. To count the number of mandrill group visits to transects, we first counted 'camera visits', where a camera took videos at intervals of $<30 \mathrm{~min}$ (O'Brien et al. 2003). We regarded visits as group 
250 visits only when two or more reproductive females, juveniles, or infants passed within $5 \mathrm{~m}$ of

251 a camera. Next, we calculated time intervals between consecutive group visits recorded by cameras along the same transect and plotted a density curve. We used only intervals of less than 3 days $(\mathrm{N}=157)$ and excluded night-time $(18: 00-06: 00 \mathrm{~h})$ from the intervals. The curve showed an exponent function-like shape with a clear change in slope at 10 hours, so we pooled camera-based group visits recorded within 10 hours (excluding night-time) by cameras along the same transect. That is, we regarded group visits filmed in the same transect at an interval of $>10 \mathrm{~h}$ or recorded in different transects, as independent. Finally, we counted independent group visits for each transect and season, and calculated capture rates as the number of independent group visits divided by the total number of days when cameras worked.

\section{Habitat Parameters}

262 We categorised habitat types of the transects in secondary forests as 'disturbed' and those in riverine forests as 'seasonally inundated' habitats. We quantified the topographic steepness of all transects by measuring the inclination of the ground in front of each camera-trap using a laser range finder (Laser Technology TruPulse ${ }^{\circledR}$ 200, Centennial, CO). We used the mean of the inclination angles as an indicator of the steepness of transects.

\section{Statistical Analysis}

269 We performed all statistical analyses using R version 3.3.3 (R Core Team 2017). All statistical 270 tests were performed as two-tailed tests, and we considered $P<0.05$ as significant.

Diet Seasonality

273 We examined seasonal variation in the relative volume of each food type in faecal samples, except for flower, vertebrate and other, which rarely occurred in faecal samples. Since the 
275 relative volumes are non-binomial, we logit-transformed them using the following equation

276 based on a previous study (Warton and Hui 2011): $z=\log ([y+0.05] /[1-y+0.05])$, where $y$ is a

277 relative volume. We added 0.05 to both the numerator and denominator of the logit function,

278 because the simple logit function does not accept 0 . We then constructed linear mixed models

279 (LMMs) using the lmer function in the lme4 package (Bates et al. 2015). The full model

280 contained the response variable logit-transformed relative volume (z), a fixed effect of season

281 (four-level categorical variable with fruit-peak season as a control level), and a random effect

282 of date of group follow (random intercept). We included the date of group follows as a random

283 effect because we collected multiple faecal samples in each group follow. We did not include

284 the number of fruit clusters as a fixed effect in the model, because we did not conduct the fruit

285 census before 2012 and we collected faecal samples both along the transects and elsewhere in

286 the study area.

To explore the statistical differences in the relative volumes among seasons, we used the 'grouping model comparison' (Mori et al. 2009). We generated 15 candidate models, including a full model where all four seasons were different levels, 13 possible 'group' models where two or more seasons were grouped as identical levels, and a null model where all the seasons were regarded as a single level. We conducted model selection based on AIC values (Akaike 1974) and probabilities that a given model has the smallest AIC among the candidate models (model selection frequencies, Burnham and Anderson 2002) from a non-parametric bootstrap of 1,000 replicates. We considered models with a model selection frequency of $\geq 5 \%$ as confident models (Shimodaira 1998) and used them to interpret the results. We checked the residual plots and normal Q-Q plots of both the full model and the smallest-AIC model for diagnostics and confirmed model stability.

To examine seasonality in the number of food types, we constructed a generalised linear mixed model (GLMM) with a binomial error distribution and a logit link function using 
300 the glmer function in the lme4 package. We used the number of food types (except 'flowers',

301 'vertebrates' and 'others') in a faecal sample as the response variable (integer variable of 1-6).

302 The full model also contained a fixed effect of season and a random effect of date of group

303 follow. We evaluated differences across seasons using the grouping model comparison,

304 followed by model selection and diagnostics similar to those described above.

305

306 Habitat Use Seasonality

307 To examine the influence of fruit availability and other environmental factors on the capture

308 rates, we constructed a GLMM with a Poisson error distribution and a log link function, using

309 the glmer function. We created a data set by counting the number of independent group visits

310 for each transect and season. The full model contained a response variable of the number of

311 group visits (integer variable) corrected by an offset of $\log$ (camera-days), fixed effects of mean

312 number of the 'important'fruit clusters (continuous variable), season, the interaction between

313 mean number of the 'important' fruit clusters and season, and three habitat parameters

314 (steepness (continuous variable), seasonally inundated habitat and disturbed habitat (binary

315 variables of Yes or No)), and a random effect of transect (random intercept). We standardised

316 all the continuous variables. We included an interaction between the number of fruits and

317 season because the effect of fruit availability on habitat preference may differ between seasons.

318 We generated 40 candidate models using all possible combinations of the fixed effects and

319 conducted model selection and diagnostics as for the analysis of diet seasonality.

320 To test for seasonality in ranging patterns, we calculated variances in capture rates

321 across transects for each season and compared them among the four seasons using a Levene's

322 test (Levene 1960). If the result of the Levene's test was significant, we then tested the

323 differences in variance for all pairwise comparisons using F tests with a Holm's p-value

324 adjustment. Large variances of capture rates indicated seasonally intensive use of particular 
transects, whereas small variances meant an even distribution of habitat use.

326

327 Ethical Note

328 This study complied with the IPS Code of Best Practices for Field Primatology and the laws

329 of the Gabonese Republic and was conducted with approval from the Centre National de la

330 Recherche Scientifique et Technologique

331 ( N $^{\circ}$ AR0031/11/MENESRSIC/CENAREST/CG/CST/CSAR) and the Agence Nationale des

332 Parcs

Nationaux

( ${ }^{\circ} 000017 / \mathrm{PR} / \mathrm{ANPN} / \mathrm{SE} / \mathrm{CS} / \mathrm{AEPN}$,

$333 \quad \mathrm{~N}^{\circ}$ 000022/PR/ANPN/SE/CS/AEPN).

334

335 Data Availability

336 The datasets during and/or analysed during the current study are available from the

337 corresponding author on reasonable request.

Results

\section{$340 \quad$ Fruiting Phenology}

341 We conducted the monthly fallen fruit census in 240 transect-months from January 2012 to

342 November 2013. We could not census in the other 13 transect-months (Fig. 2), because it was

343 impossible to access to the transects due to logistic problems. This lack of data may mean that

344 we underestimate variance in the number of fruit clusters across transects, and underestimate

345 the mean for February 2013. The number of fruit clusters of all species showed a seasonal

346 pattern: numbers were largest in December-February, decreased substantially in March-May,

347 reached their lowest numbers in June-August, and increased again in September-November

348 (Table 1, Fig. 2). The differences among the four seasons were all statistically significant

349 (Table 1). 
350 Table 1 Seasonal comparisons of the numbers of fallen fruit clusters on transects in

351 Moukalaba-Doudou National Park, Gabon, January 2012-November 2013.

\begin{tabular}{|c|c|c|c|c|c|}
\hline \multirow[t]{2}{*}{ Season } & \multirow{2}{*}{$\begin{array}{l}\text { Number of } \\
\text { transect-months }\end{array}$} & \multirow{2}{*}{$\begin{array}{l}\text { Number of all fruit } \\
\text { clusters per km } \\
\text { (Mean } \pm \text { SD) }\end{array}$} & \multicolumn{3}{|c|}{ Welch t-test with the Holm's p-value adjustment } \\
\hline & & & $\begin{array}{l}\text { vs. early fruit- } \\
\text { scarce }\end{array}$ & $\begin{array}{l}\text { vs. late fruit- } \\
\text { scarce }\end{array}$ & $\begin{array}{l}\text { vs. fruit- } \\
\text { increase }\end{array}$ \\
\hline Fruit-peak & 50 & $36.3 \pm 13.9$ & $\mathrm{t}=13.0$ & $\mathrm{t}=14.0$ & $\mathrm{t}=7.4$ \\
\hline (Dec.-Feb.) & & & $P<0.001$ & $P<0.001$ & $P<0.001$ \\
\hline Early fruit-scarce & 58 & $9.9 \pm 3.9$ & - & $\mathrm{t}=2.7$ & $\mathrm{t}=-8.4$ \\
\hline (Mar--May) & & & & $P=0.009$ & $P<0.001$ \\
\hline Late fruit-scarce & 66 & $8.2 \pm 3.0$ & - & - & $\mathrm{t}=-13.8$ \\
\hline (Jun.-Jul.) & & & & & $P<0.001$ \\
\hline Fruit-increase & 66 & $19.7 \pm 8.6$ & - & - & - \\
\hline (Sep.-Nov.) & & & & & \\
\hline
\end{tabular}

352

353

354 


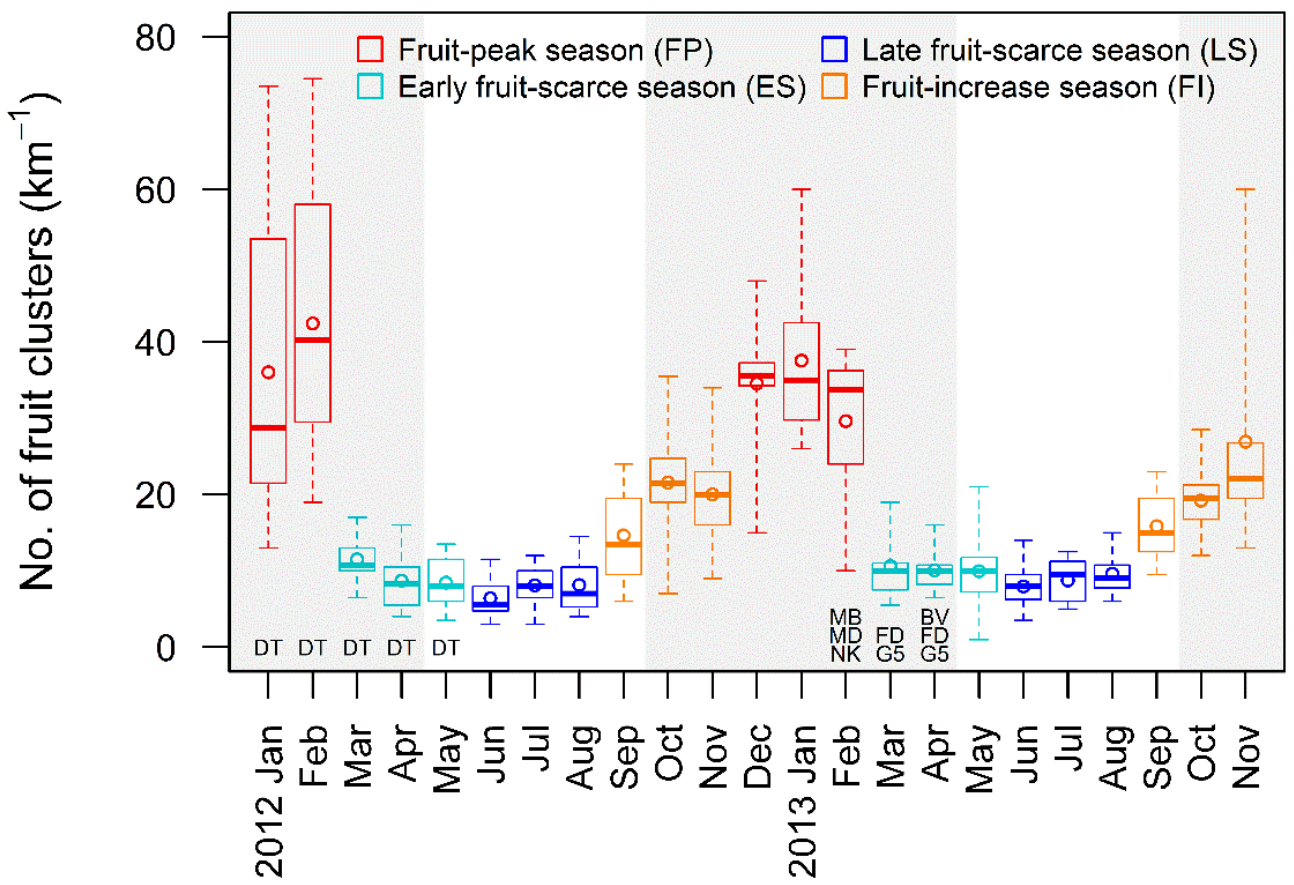

356 Fig. 2 Seasonality in the number of fallen fruit clusters on transects in Moukalaba-Doudou

357 National Park, Gabon (January 2012-November 2013). Circles show monthly means,

358 horizontal lines in boxes show monthly medians, boxes show inter-quartile ranges, and

359 whiskers show ranges. Characters below boxes indicate transect IDs where the census was

360 not conducted (see also Fig. 1). White and shaded area indicate the dry and rainy seasons,

361 respectively.

362

363

\section{Seasonality in Diet}

We sought mandrill groups on 432 days and located them on 49 days, during which we followed groups for a mean of 4.1 hours per day (range: $0.2-10.1 \mathrm{~h}$ ) and collected a mean of 12.3 faeces (range: 2-52). We analysed 417 faecal samples and distinguished 54 fruit items: we identified 31 items to species and 12 items to genus (Table 2); the remaining 11 items were unclassified. We classified 22 fruit items (17 species and five genera) as 'important' fruits for mandrill groups (Table 2). 
371 Table 2 Fruit items identified in mandrill faecal samples in Moukalaba-Doudou National Park, Gabon, August

372 2009-September 2013.

\begin{tabular}{lllllll}
\hline Fruit item & Family & Food & Season & & & \\
\cline { 5 - 7 } & & type & Fruit-peak & Early fruit- & Late fruit- & Fruit- \\
& & & (Dec.-Feb.) & scarce & scarce & increase \\
& & & (Mar.-May) & (Jun.-Aug.) & (Sep.-Nov.)
\end{tabular}

Aframomum spp.
Anthocleista vogelii
Anthonotha sp.
Bombax chevalieri

Caloncoba welwitschii

Ceiba pentandra

Cissus dinklagei

Cola spp.

Coula edulis

Daniellia klainei

Desplatsia sp.

Dialium sp.

Diogoa zenkeri

Diospyros spp.

Discoglypremna caloneura

Drypetes sp.

Duboscia macrocarpa

Ficus spp.

Gambeya africana

Grewia coriacea

Hexalobus crispiflorus

Irvingia gabonensis

Klainedoxa gabonensis

Laccosperma sp.

Landolphia spp.

Meiocarpidium lepidotum

Mimusops zeyheri

Musanga cecropioides

Myrianthus arboreus

Pentaclethra macrophylla

Polyalthia suaveolens

Porterandia cladantha

Pseudospondias longifolia

Sacoglottis gabonensis

Salacia spp.

Santiria trimera

Staudtia gabonensis

Synsepalum dulcificum

\begin{tabular}{ll} 
Zingiberaceae & F \\
Gentianaceae & F \\
Fabaceae & S \\
Bombacaceae & S \\
Flacourtiaceae & F \\
Bombacaceae & S \\
Vitaceae & F \\
Sterculiaceae & F, S \\
Olacaceae & S \\
Fabaceae & S \\
Tiliaceae & F \\
Fabaceae & F, S \\
Olacaceae & S \\
Ebenaceae & S \\
Euphorbiaceae & S \\
Putranjivaceae & F \\
Tiliaceae & F, S \\
Moraceae & F \\
Sapotaceae & F \\
Tiliaceae & F \\
Annonaceae & F \\
Irvingiaceae & F \\
Irvingiaceae & F, S \\
Arecaceae & F \\
Apocynaceae & F, S \\
Annonaceae & F, S \\
Sapotaceae & F \\
Cecropiaceae & F \\
Cecropiaceae & F \\
Fabaceae & S \\
Annonaceae & S \\
Rubiaceae & F \\
Anacardiaceae & F \\
Humiriaceae & F, S \\
Celastraceae & F \\
Burseraceae & F \\
Myristicaceae & F \\
Sapotaceae & F \\
& \\
\hline
\end{tabular}

(Mar.-May) (Jun.-Aug.) (Sep.-Nov.) 


$\begin{array}{llll}\text { Tabernanthe iboga } & \text { Apocynaceae } & \text { F, S } & \circ \\ \text { Treculia africana } & \text { Moraceae } & \text { F } & \circ \\ \text { Uapaca guineensis } & \text { Phyllanthaceae } & \text { F, S } & \\ \text { Uvaria } \text { sp. } & \text { Annonaceae } & \text { F } & \\ \text { Uvariastrum pierreanum } & \text { Annonaceae } & \text { F } & \bullet\end{array}$

373 Food type: $\mathrm{F}=$ fruit fibre, $\mathrm{S}=$ crushed seeds. Season: $\circ$, items found during the given seasons; $\bullet$, items identified 374 as 'important' fruits (see Methods). 
Fruit fibre and crushed seeds both occurred in a large proportion of the faecal remains,

377 but their seasonal patterns differed. Fruit fibre occurrence was high during the fruit-peak and

378 fruit-increase seasons, and decreased substantially in the late fruit-scarce season (Fig. 3). The results of LMMs and AIC model selection identified two confident models which showed that relative volumes in the fruit-peak and fruit-increase seasons (mean relative volume $=45.0 \%$ )

381 were much larger than in the early and late fruit-scarce seasons (9.3\%) (Table 3 (i), Fig. 4a).

382 In contrast, the occurrence of crushed seeds was high from the fruit-peak to the late fruit-scarce 383 season (Fig. 3). Four confident models (Table 3 (ii)) showed that relative volumes were largest

384 in the fruit-peak and late fruit-scarce seasons (mean relative volume $=42.6 \%$ ), smallest in the 385 fruit-increase season (9.3\%), and intermediate in early the fruit-scarce season (22.8\%) (Fig. 3864 b). Most of the seeds found in faeces of fruit-scarce seasons were finely crushed and 387 unidentifiable, but we identified Coula edulis nuts and Sacoglottis gabonensis seeds as 388 'important' foods in fruit-scarce seasons, when these species do not produce many fruits 389 (Table 2). 


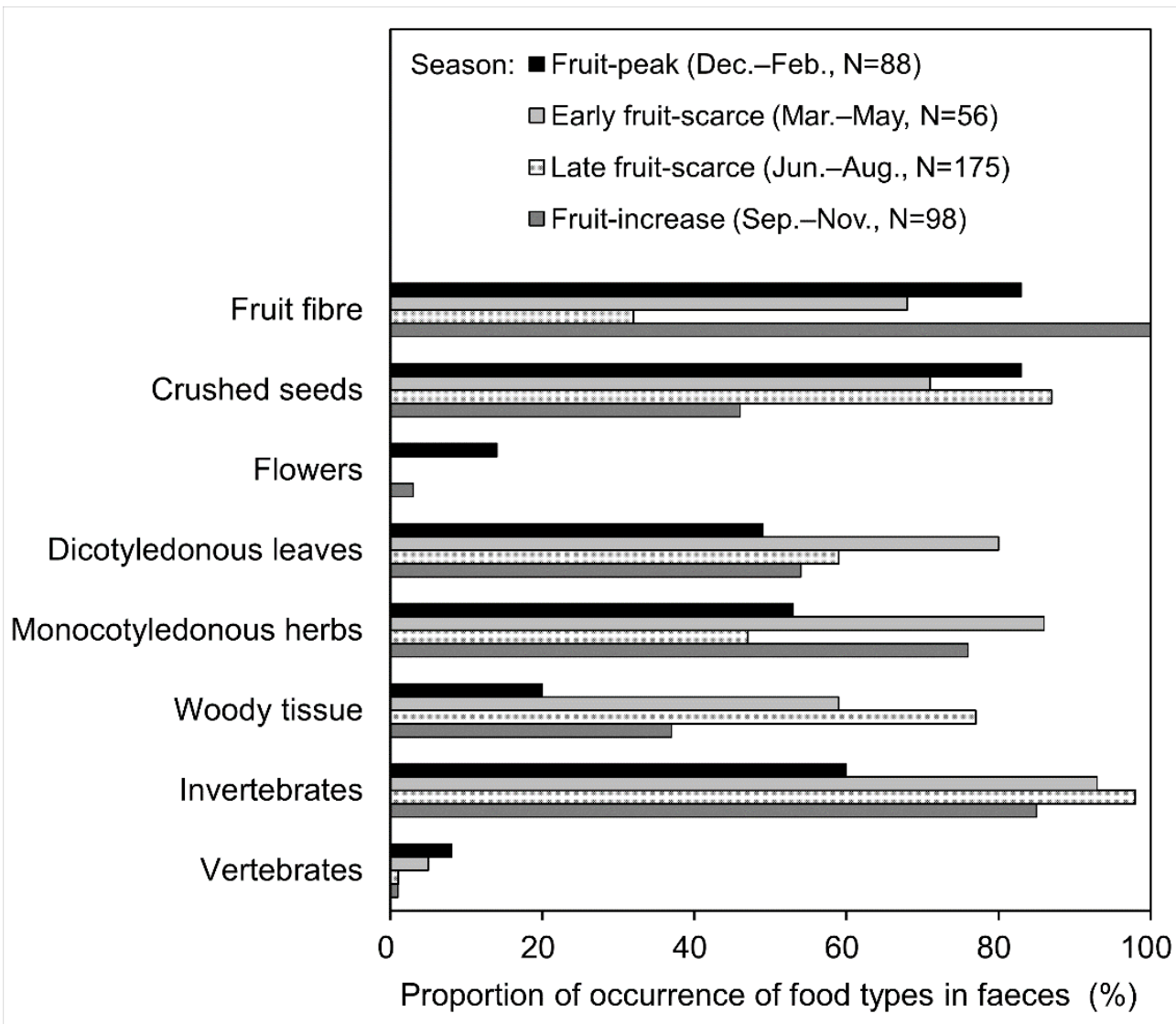

391 Fig. 3 Seasonality in the occurrence of food types in mandrill faeces (number of faeces containing a food type divided by the total number of faeces) in Moukalaba-Doudou National Park, Gabon (August 2009-September 2013).

Non-fruit vegetable foods (dicotyledonous leaves, monocotyledonous herbs, and

396 woody tissue) in faeces showed different seasonal patterns. Relative volumes of

397 dicotyledonous leaves showed no seasonal pattern (mean relative volume $=15.6 \%$ )

398 (Table 3 (iii), Fig. 4c). Mandrills fed on the pith of Aframomum spp. (Zingiberaceae),

399 Marantochloa spp. (Marantaceae), and on Palisota hirsuta (Commelinaceae), and blades of

400 forest grasses (Poaceae) in various seasons. Relative volumes of monocotyledonous herbs

401 were larger in the early fruit-scarce and fruit-increase seasons (mean relative volume $=20.0 \%$ )

402 than in the fruit-peak and late fruit-scarce seasons (8.4\%) (Table 3 (iv), Fig. 4d). Conversely, 
403 woody tissue showed a clear seasonal pattern. Proportions of occurrence in the early and late

404 fruit-scarce seasons were twice as high as those in the other seasons (Fig. 3), and relative

405 volumes in the early and late fruit-scarce seasons (mean relative volume $=17.5 \%$ ) were much

406 larger than those in the fruit-peak and fruit-increase seasons (4.4\%) (Table 3 (v), Fig. 4e).

407 Invertebrates, mainly ants (Formicidae) and grasshoppers (Acrididae), occurred

408 frequently in faeces (Fig. 3) but at consistently low relative volumes (Fig. 4f). The relative

409 volumes were stable from early fruit-scarce to fruit-increase seasons (mean relative volume $=$

$41012.5 \%$ ), and decreased in the fruit-peak seasons (7.5\%) (Table 3 (vi)).

411 The number of food types in faeces varied seasonally. Numbers were smallest in the

412 fruit-peak season (mean number of food types $=3.5$ ), largest in the early fruit-scarce season

413 (4.5), and intermediate in the late fruit-scarce and fruit-increase seasons (4.0) (Table 3 (vii)). 


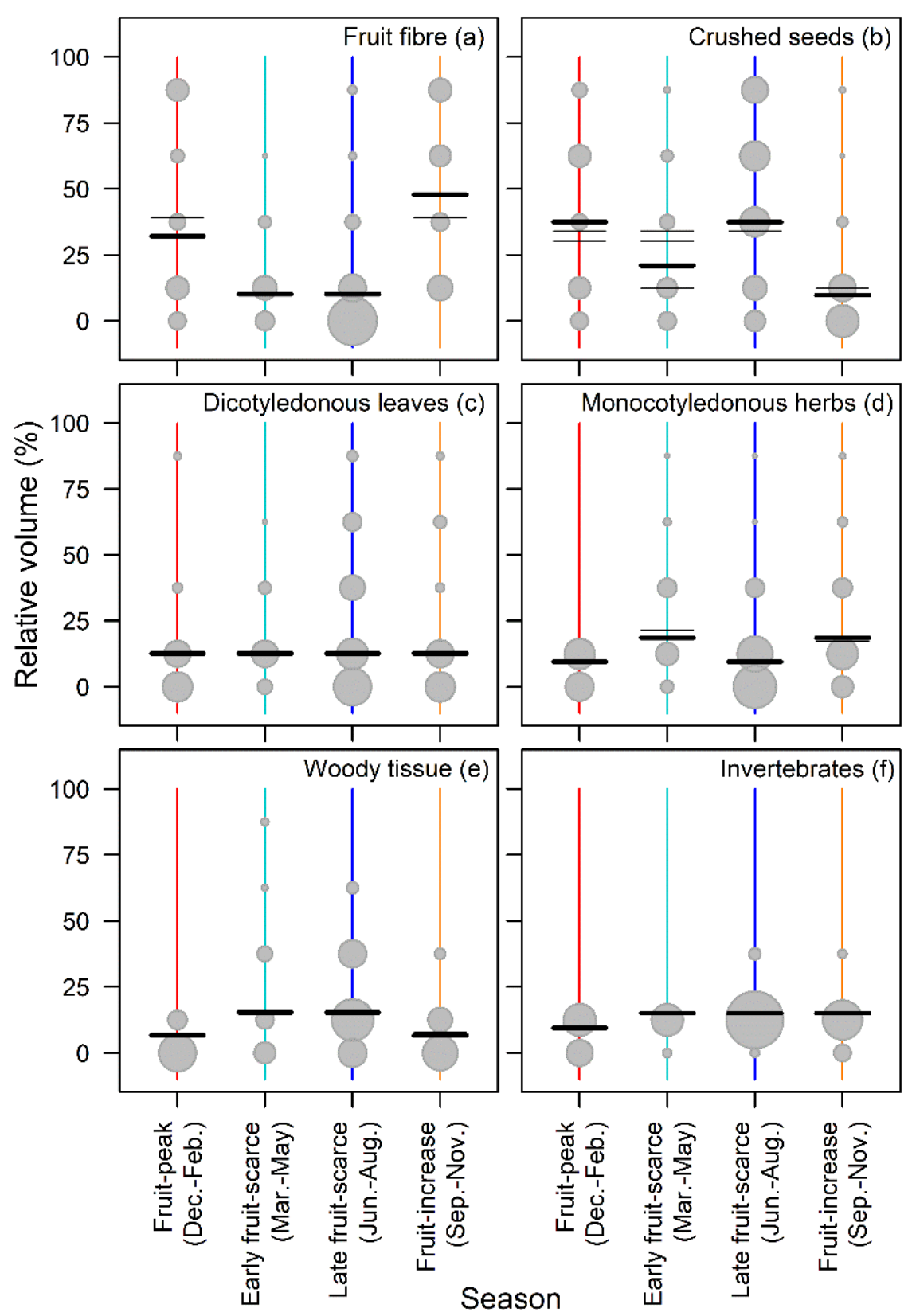

415 Fig. 4 Seasonality in relative volumes of fruit fibre, crushed seeds, dicotyledonous leaves,

416 monocotyledonous herbs, woody tissue, and invertebrates in mandrill faecal samples from

417 Moukalaba-Doudou National Park, Gabon (August 2009-September 2013). Areas of grey

418 circles are proportional to the number of faecal samples. Bold horizontal lines and fine

419 horizontal lines show estimates of the smallest-AIC models and those of the other confident models, respectively. 
421 Table 3 Models of mandrill diet seasonality in Moukalaba-National Park, Gabon (August 2009-September 2013, N = 417). Model rank is based on 422 AIC, and the table includes only the 'confident models', with model selection frequencies of $\geq 0.05$.

\begin{tabular}{|c|c|c|c|c|c|c|c|c|}
\hline \multirow[t]{3}{*}{ Rank } & \multirow[t]{3}{*}{ Model $^{\mathrm{a}}$} & \multirow[t]{3}{*}{ AIC } & \multirow{3}{*}{$\begin{array}{l}\text { Model } \\
\text { selection } \\
\text { frequency }\end{array}$} & \multicolumn{4}{|c|}{ Fixed effect (estimate $\pm \mathrm{SE}$ ) } & \multirow{3}{*}{$\begin{array}{l}\text { Random effect } \\
\text { (estimate) }\end{array}$} \\
\hline & & & & \multicolumn{4}{|l|}{ Season } & \\
\hline & & & & $\begin{array}{l}\text { Fruit-peak } \\
\text { (Dec.-Feb.) [a] }\end{array}$ & $\begin{array}{l}\text { Early fruit-scarce } \\
\text { (Mar.-May) }[\mathrm{b}]\end{array}$ & $\begin{array}{l}\text { Late fruit-scarce } \\
\text { (Jun.-Aug.) [c] }\end{array}$ & $\begin{array}{l}\text { Fruit-increase } \\
\text { (Sep.-Nov.) [d] }\end{array}$ & \\
\hline \multicolumn{9}{|c|}{ (i) Relative volume of fruit fibre (logit-transformed LMM) } \\
\hline 1 & {$[\mathrm{a}][\mathrm{bc}][\mathrm{d}]$} & 1278.1 & 0.729 & $-0.75 \pm 0.26$ & $-2.18 \pm 0.24$ & (identical to $[\mathrm{b}]$ ) & $-0.08 \pm 0.28$ & 0.97 \\
\hline 1 & {$[\mathrm{ac}][\mathrm{b}][\mathrm{d}]$} & 1289.9 & 0.804 & $-0.51 \pm 0.21$ & $-1.33 \pm 0.46$ & (identical to [a]) & $-2.22 \pm 0.30$ & 1.07 \\
\hline 2 & {$[\mathrm{abc}][\mathrm{d}]$} & 1290.9 & 0.068 & $-0.66 \pm 0.20$ & (identical to [a]) & (identical to [a]) & $-2.22 \pm 0.31$ & 1.10 \\
\hline 3 & {$[\mathrm{ac}][\mathrm{bd}]$} & 1291.1 & 0.055 & $-0.51 \pm 0.22$ & $-1.94 \pm 0.26$ & (identical to [a]) & (identical to $[\mathrm{b}]$ ) & 1.09 \\
\hline 5 & {$[a b][c][d]$} & 1291.3 & 0.068 & $-0.84 \pm 0.24$ & (identical to $[\mathrm{a}]$ ) & $-0.32 \pm 0.33$ & $-2.22 \pm 0.31$ & 1.09 \\
\hline \multicolumn{9}{|c|}{ (iii) Relative volume of dicotyledonous leaves (logit-transformed LMM) } \\
\hline 1 & [abcd] & 1209.9 & 0.949 & $-1.93 \pm 0.13$ & (identical to $[\mathrm{a}]$ ) & (identical to [a]) & (identical to [a]) & 0.86 \\
\hline \multicolumn{9}{|c|}{ (v) Relative volume of woody tissue (logit-transformed LMM) } \\
\hline 1 & {$[\mathrm{ad}][\mathrm{bc}]$} & 1043.7 & 0.893 & $-2.64 \pm 0.11$ & $-1.71 \pm 0.13$ & (identical to $[\mathrm{b}]$ ) & (identical to [a]) & 0.50 \\
\hline 2 & {$[\mathrm{a}][\mathrm{bc}][\mathrm{d}]$} & 1044.9 & 0.097 & $-2.78 \pm 0.15$ & $-1.71 \pm 0.13$ & (identical to $[\mathrm{b}]$ ) & $-2.48 \pm 0.15$ & 0.50 \\
\hline \multicolumn{9}{|c|}{ (vi) Relative volume of invertebrates (logit-transformed LMM) } \\
\hline 1 & {$[\mathrm{a}][\mathrm{bcd}]$} & 570.3 & 0.982 & $-2.26 \pm 0.07$ & $-1.73 \pm 0.05$ & (identical to $[\mathrm{b}]$ ) & (identical to $[\mathrm{b}]$ ) & 0.00 \\
\hline \multicolumn{9}{|c|}{ (vii) Number of food types (binomial GLMM) } \\
\hline 1 & {$[\mathrm{a}][\mathrm{b}][\mathrm{cd}]$} & 334.8 & 0.898 & $0.33 \pm 0.09$ & $1.16 \pm 0.13$ & $0.70 \pm 0.07$ & (identical to [c]) & 0.10 \\
\hline
\end{tabular}

423 a. "Model" column shows grouping patterns of seasons: for example, the smallest-AIC model for relative volume of fruit fibre (i.e., [a][bc][d]) indicates that relative 424 volumes in the early and late fruit-scarce seasons were estimated to be identical, and that the other combinations were estimated to be different each other. 


\section{Seasonality in Habitat Use}

426 We calculated capture rates in 87 transect-seasons from January 2012 to November 2013 (total camera-days $=54,541$ ). We identified 155 independent group visits on 169 days (overall capture rate $=0.0028$ visit/camera-day). Groups visited two different transects on 14 days but never three or more transects on any given day. Given that the estimated mean ranging speed of groups in the study area is $0.9 \mathrm{~km} / \mathrm{h}$ (Hongo 2016), all but one case of these visits to two different transects were too distant for a group to arrive within the time intervals of the visits, suggesting that they were unlikely to be two consecutive visits by the same group.

We identified seven confident models showing that the mean number of 'important'

434 fruit clusters affected the capture rates positively, and that habitat disturbance had a negative 435 effect on capture rates (Table 4). Four of these models also included the interaction term 436 between important fruits and season. According to the second smallest-AIC model, which had 437 the highest model selection frequency, the mean number of important fruit clusters correlated positively with capture rates in the fruit-peak and fruit-increase seasons, but correlations in the early and late fruit-scarce seasons were not reliable, as the standard errors of the interaction term were large (Fig. 5, Table 4). Although some models included other habitat parameters, the effects were unclear because their standard errors were large (Table 4). $\left.\mathrm{F}=13.9, P=2.1 \times 10^{-7}\right)$. Post hoc pairwise comparisons showed that the variance in the fruit-

444 peak season was significantly higher than in the other seasons (Table 5). In fruit-peak seasons, 445 cameras in more than half of the transects recorded no mandrill groups, and capture rates of 446 transects DB and DT were particularly high (Fig. $6(\mathrm{a}, \mathrm{e})$ ). In contrast, in most of the other 447 seasons, cameras in most transects recorded groups at relatively lower rates (Fig. 6). 


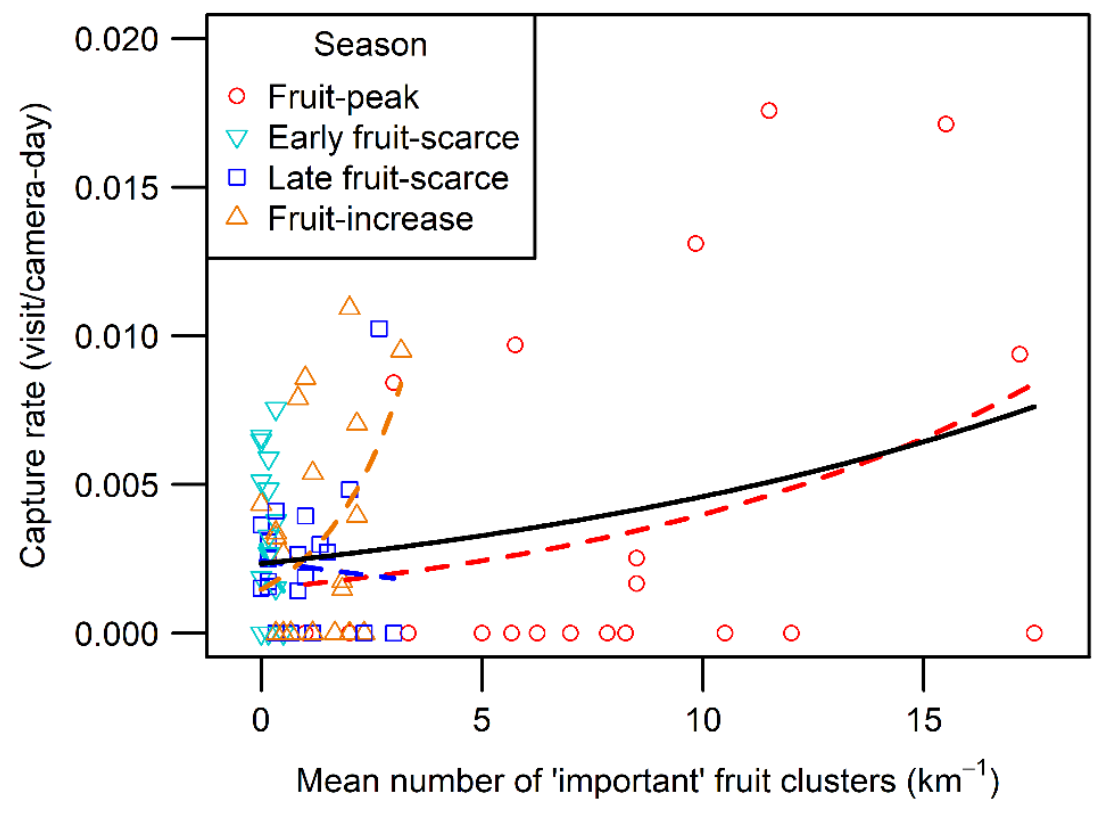

450 Fig. 5 The influence of the number of 'important' fruit clusters and season on camera-trap

451 capture rates of mandrill groups in Moukalaba-Doudou National Park, Gabon (January 2012-

452 November 2013). Data points represent values for individual transect-seasons. Solid black line

453 shows the regression curve of the smallest-AIC model, whereas dashed lines show those of

454 the second smallest-AIC model, which had the highest model selection frequency. 
457 Table 4 Models of seasonality in habitat use by mandrill groups in Moukalaba-National Park, Gabon (January 2012-November 2013, N = 87).

458 Model rank is based on AIC, and the table includes only 'confident models', with model selection frequencies of $\geq 0.05$.

\begin{tabular}{|c|c|c|c|c|c|c|c|}
\hline Rank & 1 & 2 & 3 & 5 & 6 & 7 & 9 \\
\hline Model & $\beta_{1}, \beta_{4}$ & $\beta_{1}, \beta_{2}, \beta_{1} \times \beta_{2}, \beta_{4}$ & $\beta_{1}, \beta_{2}, \beta_{4}$ & $\beta_{1}, \beta_{2}, \beta_{1} \times \beta_{2}, \beta_{4}, \beta_{5}$ & $\beta_{1}, \beta_{2}, \beta_{1} \times \beta_{2}, \beta_{3}, \beta_{4}$ & $\beta_{1}, \beta_{2}, \beta_{4}, \beta_{5}$ & $\beta_{1}, \beta_{2}, \beta_{1} \times \beta_{2}, \beta_{3}, \beta_{4}, \beta_{5}$ \\
\hline AIC & 170.5 & 170.7 & 171.6 & 171.6 & 172.1 & 172.2 & 172.5 \\
\hline $\begin{array}{l}\text { Model selection } \\
\text { frequency }\end{array}$ & 0.136 & 0.300 & 0.117 & 0.109 & 0.073 & 0.056 & 0.082 \\
\hline \multicolumn{8}{|l|}{ Fixed effect (estimate \pm SE) } \\
\hline Intercept & $-5.88 \pm 0.22$ & $-6.25 \pm 0.42$ & $-6.40 \pm 0.41$ & $-6.17 \pm 0.42$ & $-6.22 \pm 0.42$ & $-6.32 \pm 0.41$ & $-6.12 \pm 0.41$ \\
\hline $\begin{array}{l}\text { Mean number of 'important' } \\
\text { fruit clusters }\left[\beta_{1}\right]\end{array}$ & $0.27 \pm 0.07$ & $0.39 \pm 0.17$ & $0.49 \pm 0.16$ & $0.42 \pm 0.17$ & $0.39 \pm 0.17$ & $0.52 \pm 0.17$ & $0.42 \pm 0.17$ \\
\hline \multicolumn{8}{|l|}{ Season $\left[\beta_{2}\right]$} \\
\hline Early fruit-scarce & - & $-3.46 \pm 3.83$ & $0.65 \pm 0.49$ & $-3.14 \pm 3.83$ & $-3.41 \pm 3.81$ & $0.72 \pm 0.50$ & $-2.94 \pm 3.81$ \\
\hline Late fruit-scarce & - & $-0.01 \pm 0.54$ & $0.48 \pm 0.45$ & $0.07 \pm 0.55$ & $-0.03 \pm 0.54$ & $0.54 \pm 0.45$ & $0.06 \pm 0.55$ \\
\hline Fruit-increase & - & $1.18 \pm 0.45$ & $0.82 \pm 0.43$ & $1.23 \pm 0.46$ & $1.20 \pm 0.45$ & $0.88 \pm 0.44$ & $1.28 \pm 0.46$ \\
\hline \multicolumn{8}{|c|}{ Interaction between number of 'important' fruit clusters and season $\left[\beta_{1} \times \beta_{2}\right]$} \\
\hline Early fruit-scarce & - & $-6.27 \pm 6.03$ & - & $-5.86 \pm 6.02$ & $-6.18 \pm 6.01$ & - & $-5.55 \pm 5.99$ \\
\hline Late fruit-scarce & - & $-0.77 \pm 0.84$ & - & $-0.72 \pm 0.84$ & $-0.78 \pm 0.84$ & - & $-0.73 \pm 0.84$ \\
\hline Fruit-increase & - & $1.80 \pm 0.80$ & - & $1.77 \pm 0.79$ & $1.91 \pm 0.81$ & - & $1.92 \pm 0.81$ \\
\hline Steepness $\left[\boldsymbol{\beta}_{3}\right]$ & - & - & - & - & $-0.17 \pm 0.22$ & - & $-0.21 \pm 0.20$ \\
\hline Disturbed habitats $\left[\beta_{4}\right]$ & $-1.97 \pm 0.66$ & $-2.02 \pm 0.70$ & $-1.94 \pm 0.66$ & $-2.12 \pm 0.67$ & $-2.16 \pm 0.71$ & $-2.04 \pm 0.63$ & $-2.29 \pm 0.67$ \\
\hline $\begin{array}{l}\text { Seasonally inundated } \\
\text { habitats }\left[\beta_{5}\right]\end{array}$ & - & - & - & $-0.58 \pm 0.53$ & - & $-0.59 \pm 0.49$ & $-0.67 \pm 0.51$ \\
\hline \multicolumn{8}{|l|}{ Random effect (estimate) } \\
\hline SD of transect & 0.58 & 0.63 & 0.58 & 0.57 & 0.61 & 0.51 & 0.53 \\
\hline
\end{tabular}


460 Table 5 Seasonal comparisons of variance in camera-trap capture rates of mandrill groups in

461 Moukalaba-Doudou National Park, Gabon (January 2012-November 2013).

\begin{tabular}{|c|c|c|c|c|c|}
\hline \multirow[t]{4}{*}{ Season } & \multirow{4}{*}{$\begin{array}{l}\text { Total } \\
\text { number of } \\
\text { transects }\end{array}$} & \multirow{4}{*}{$\begin{array}{l}\text { Variance in } \\
\text { capture rates } \\
\text { across transects } \\
\text { (camera-days }{ }^{-2} \text { ) }\end{array}$} & \multicolumn{3}{|c|}{ F test with Holm's p-value adjustment } \\
\hline & & & vs. Early & vs. Late & vs. Fruit- \\
\hline & & & fruit-scarce & fruit-scarce & increase \\
\hline & & & & & \\
\hline \multirow[t]{2}{*}{ Fruit-peak } & 22 & $5.0 \times 10^{-5}$ & $\mathrm{~F}=7.1$ & $\mathrm{~F}=9.4$ & $\mathrm{~F}=4.1$ \\
\hline & & & $P<0.001$ & $P<0.001$ & $P=0.008$ \\
\hline Early fruit- & $21 *$ & $7.0 \times 10^{-6}$ & - & $\mathrm{F}=1.3$ & $\mathrm{~F}=0.58$ \\
\hline scarce & & & & $P=0.54$ & $P=0.44$ \\
\hline Late fruit- & 22 & $5.4 \times 10^{-6}$ & - & - & $F=0.44$ \\
\hline scarce & & & & & $P=0.19$ \\
\hline Fruit- & 22 & $1.2 \times 10^{-5}$ & - & - & - \\
\hline increase & & & & & \\
\hline
\end{tabular}




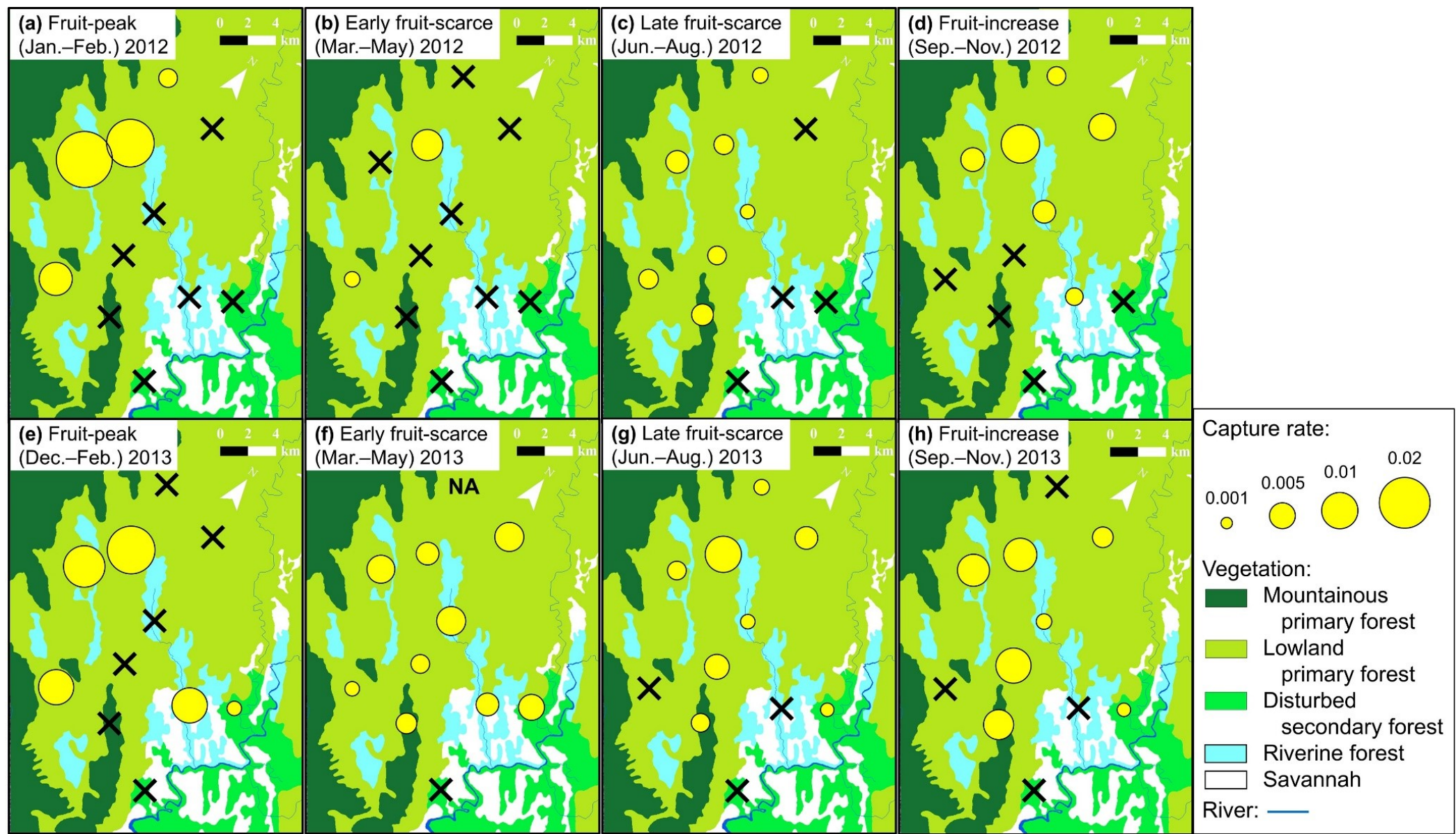

465

Fig. 6 Camera-trap capture rates for mandrill groups in each season in Moukalaba-Doudou National Park, Gabon (January 2012-November 2013).

466

$X$ indicates no mandrill groups were filmed. ' $N A$ ' in (f) means no camera worked during the season. 


\section{Discussion}

469 We found seasonal changes in diet and habitat use patterns in wild mandrill groups. In fruitrich seasons, mandrill faeces contained a high proportion of fruit fibre, and groups visited transects where fruit production was high intensively. In contrast, in fruit-scarce seasons, crushed seeds made up a large volume of the faecal samples, the proportion of woody tissue and the number of food types increased. Groups also visited larger numbers of transects, and their visit frequencies were distributed more uniformly in fruit-scarce seasons. number of food types was smallest in the fruit-peak season, although faeces contained multiple food types year-round. These results suggest that mandrills at Moukalaba-Doudou are omnivorous year-round but become more frugivorous when fruits are available. The relative volume of crushed seeds was high even in fruit-scarce seasons, and seeds of several species that do not produce many fruits in these seasons appeared in faeces frequently, suggesting that mandrills in the study area respond to seasonal fruit scarcity by foraging on buried seeds. These dietary patterns are in common with mandrills at other sites (Rogers et al. 1996; Tutin et al. 1997; White 2007) and drills in lowland forests (Astaras and Waltert 2010). Increased dietary diversity during food scarcity is also a common strategy for other African primates (Hemingway and Bynum 2005).

The relative volume of woody tissue increased in fruit-scarce seasons, but that of monocotyledonous herbs did not show a seasonal pattern according to fruiting phenology. These results differ from previous findings, where mandrills increase their herb consumption when fruits are scarce (Hoshino 1985; Tutin et al. 1997), and may imply within-species variation in feeding strategy, as observed in drills on Bioko Island (Owens et al. 2015). Herbs and woody tissue are both low-quality foods, which are common alternative foods for large-

492 sized monkeys (Hemingway and Bynum 2005). Mandrills have powerful fore limb flexion 
493 (Fleagle and McGraw 2002), which may enable them to excavate roots and subterranean stems

494 buried in leaf litter.

495 Camera-trap capture rates of mandrill groups showed positive correlations with

496 availability of 'important' fruits in fruit-rich seasons. Moreover, group visits in fruit-peak

497 seasons were highly biased toward two or three transects, whereas those in the other seasons

498 were more uniformly distributed across most of the transects. These results suggest seasonal

499 changes in mandrill habitat use. In fruit-rich seasons, mandrill groups in our study area may

500 show a high selectivity for habitats where fruits are highly available, to forage on fresh fruits.

501 In contrast, during fruit-scarce seasons, when mandrills consume more uniformly-distributed

502 seeds and woody tissue, they may become less selective in fruit availability and range over a

503 much wider area. Our findings on seasonal habitat use differ from those for a mandrill group

504 at Lopé, which used gallery forests intensively regardless of season (White 2007). This

505 difference may reflect differences in habitat. At Lopé, human-introduced Elaeis guineensis

506 trees are abundant in gallery forests (Ukizintambara et al. 2007). Their fruits are available year-

507 round, and mandrills consume them frequently (White 2007). This all-year-round available

508 food may retain the group in gallery forests. At Moukalaba-Doudou, no fruit species was

509 available year-round, and therefore mandrills may need change both diets and ranging patterns

510 seasonally.

511 Habitat disturbance affected the capture rates negatively, suggesting that mandrill

512 groups avoid disturbed forests. Mandrills are large-sized, frugivorous primates and this result

513 is consistent with a general pattern where the negative effect of disturbance on habitat

514 suitability increases with body weight and degree of frugivory (Johns and Skorupa 1987). The

515 effects of seasonal inundation and steepness on the capture rates were unclear. These habitat

516 parameters may not affect mandrill habitat use: in central Gabon, mandrills are observed in

517 forests close to streams frequently (Lahm 1986), and drills range in montane forests with steep 
518 altitudinal gradients (Owens et al. 2015; Wild et al. 2005).

519 There is so far no clear evidence for seasonal range expansion in African primates,

520 but this is observed frequently in New World primates, particularly species with large home ranges (Hemingway and Bynum 2005; Terborgh 1983). The unusually large range of mandrills and heterogeneous vegetation distribution in the study area may allow them to show this flexible ranging behaviour. Moreover, our findings highlight intergeneric differences between Mandrillus and Cercocebus in adaptations to food seasonality. Although these genera share morphology adapted to hard-object eating and terrestrial foraging (Fleagle and McGraw 2002), Cercocebus species do not exhibit clear dietary seasonality (McGraw et al. 2014; Mitani 1989). This gap may come from considerable difference in group size between the genera (Swedell 2011). Seasonal change in diet and seasonal range expansion may be both important for Mandrillus species to maintain their large groups year-round, whereas changing habitat may

530 be sufficient for Cercocebus species of small group size to keep their diets stable year-round.

531 To clarify the effect of group size on behavioural flexibility in African primates, future studies should compare both dietary and ranging responses to food seasonality between closelyrelated sympatric species with different group sizes, as conducted in New World forests (Peres 1994). Mandrills and red-capped mangabeys may be good candidates for the comparison of this kind.

Our study has two limitations. First, we conducted the fruit census for two years, which covered only part of the periods when we collected faecal samples. Although fruiting

538 phenology showed a regular pattern, it may vary between years. We need longer-term studies 539 to confirm our findings. Second, we investigated seasonality in habitat use of mandrills at a 540 population level, but did not examine seasonality in group ranging behaviours per se. Field 541 studies of the ranging patterns of identified groups are needed to understand the ranging 542 seasonality of wild mandrills at a finer level. 


\section{Conclusion and Perspectives}

545 Mandrills in the study area changed their diets from highly frugivorous to more omnivorous

546 when fruit availability decreased. Groups also reduced their habitat selectivity and used

547 different habitats more evenly when fruit availability decreased. These flexible feeding 548 behaviours may allow mandrills to maintain their extremely large groups. Using different 549 habitats evenly in fruit-scarce seasons may also benefit mandrill reproduction. The mandrill 550 mating season coincides with the fruit-scarce season (Hongo et al. 2016), and large groups 551 which travel widely and contain many sexually receptive females, may favour influxes by 552 many solitary males. Receptive females may be able to mate with multiple males, including 553 subordinate males (Setchell et al. 2005), and choose among males (Setchell 2005). Future 554 studies should examine the relationships between the ranging patterns of groups and solitary 555 males.

\section{Conflict of Interest}

558 The authors declare that they have no conflict of interest.

\section{Acknowledgements}

561 We are grateful to CENAREST and ANPN for permission to conduct the study. PROCOBHA

562 members including Yuji Takenoshita, Shiho Fujita, Pierre Philippe Mbehang-Nguema, Keiko

563 Tsubokawa and Saeko Terada helped us in the field. Field assistants including Biviga Steven

564 and Nzamba Victor supported our fieldwork. Hiroshi Himori, Hikari Ishijima, Aya Kokubu, 565 and Takahiro Yamagishi assisted us in the video analysis. We appreciate Naofumi Nakagawa, 566 Juichi Yamagiwa, Michio Nakamura, Hiroshi Ihobe, Eiji Inoue, Joanna M. Setchell and two 567 anonymous reviewers for constructive comments to earlier manuscript. Marina Cords and two 
anonymous reviewers also gave comments to the manuscript submitted elsewhere. We thank

569 Editage for the English language review. This study was funded by Japan Society for the Promotion of Science (JSPS) KAKENHI (19107007 for Juichi Yamagiwa and 12J01884 for analysis; SH wrote the first draft of the paper; and YN, EFAO and FLMN improved substantially the manuscript.

\section{References}

Abernethy, K. A., White, L. J. T., \& Wickings, E. J. (2002). Hordes of mandrills (Mandrillus sphinx): extreme group size and seasonal male presence. Journal of Zoology, 258(1), 131137.

Akaike, H. (1974). A new look at the statistical model identification. IEEE Transactions on Automatic Control, 19(6), 716-723.

Astaras, C., \& Waltert, M. (2010). What does seed handling by the drill tell us about the ecological services of terrestrial cercopithecines in African forests? Animal Conservation, 13(6), 568-578.

Bates, D., Mächler, M., Bolker, B. M., \& Walker, S. C. (2015). Fitting linear mixed-effects models using lme4. Journal of Statistical Software, 67(1), 1-48.

Brockmeyer, T., Kappeler, P. M., Willaume, E., Benoit, L., Mboumba, S., \& Charpentier, M. J. (2015). Social organization and space use of a wild mandrill (Mandrillus sphinx) group.

592 Burnham, K. P., \& Anderson, D. R. (2002). Model selection and multimodel inference: a 
practical information-theoretic approach. New York, USA: Springer.

594

595

596

597

598

599

600

601

602

603

604

605

606

607

608

609

610

611

612

613

614

615

616

617

Di Bitetti, M. S. (2001). Home-range use by the tufted capuchin monkey (Cebus apella nigritus) in a subtropical rainforest of Argentina. Journal of Zoology, 253(1), 33-45.

Etiendem, D. N., Funwi-Gabga, N., Tagg, N., Hens, L., \& Indah, E. K. (2013). The Cross River gorillas (Gorilla gorilla diehli) at Mawambi Hills, South-West Cameroon: habitat suitability and vulnerability to anthropogenic disturbance. Folia Primatologica, 84(1), 18 31.

Fleagle, J. G., \& McGraw, W. S. (2002). Skeletal and dental morphology of African papionins: unmasking a cryptic clade. Journal of Human Evolution, 42(3), 267-292.

Fleagle, J. G. (2013). Primate adaptation and evolution (3 ed.). San Diego, USA: Academic Press.

Furuichi, T., Hashimoto, C., \& Tashiro, Y. (2001). Fruit availability and habitat use by chimpanzees in the Kalinzu Forest, Uganda: examination of fallback foods. International Journal of Primatology, 22(6), 929-945.

Gogarten, J. F., Bonnell, T. R., Brown, L. M., Campenni, M., Wasserman, M. D., \& Chapman, C. A. (2014). Increasing group size alters behavior of a folivorous primate. International Journal of Primatology, 35(2), 590-608.

Hanya, G., Tsuji, Y., \& Grueter, C. C. (2013). Fruiting and flushing phenology in Asian tropical and temperate forests: implications for primate ecology. Primates, 54(2), 101-110.

Harris, T. R., Chapman, C. A., \& Monfort, S. L. (2010). Small folivorous primate groups exhibit behavioral and physiological effects of food scarcity. Behavioral Ecology, 21(1), $46-56$.

Hemingway, C. A., \& Bynum, N. (2005). The influence of seasonality on primate diet and ranging. In D. K. Brockman \& C. P. van Schaik (Eds.), Seasonality in Primates: Studies of Living and Extinct Human and Non-human Primates (pp. 57-104). New York, USA: 
Cambridge University Press.

619 Holm, S. (1979). A simple sequentially rejective multiple test procedure. Scandinavian Journal of Statistics, 6(2), 65-70.

621

Hongo, S. (2014). New evidence from observations of progressions of mandrills (Mandrillus sphinx): a multilevel or non-nested society? Primates, 55(4), 473-481.

Hongo, S. (2016). Socioecology of mandrills (Mandrillus sphinx): mating and feeding tactics in a primate with extremely large group. Kyoto University, Kyoto, Japan.

Hongo, S., Nakashima, Y., Akomo-Okoue, E. F., \& Mindonga-Nguelet, F. L. (2016). Female reproductive seasonality and male influxes in wild mandrills (Mandrillus sphinx). International Journal of Primatology, 37(3), 416-437.

Hoshino, J. (1985). Feeding ecology of mandrills (Mandrillus sphinx) in Campo Animal Reserve, Cameroon. Primates, 26(3), 248-273.

Janson, C. H. (1988). Food competition in brown capuchin monkeys (Cebus apella): quantitative effects of group size and tree productivity. Behaviour, 105(1), 53-76.

Johns, A. D., \& Skorupa, J. P. (1987). Responses of rain-forest primates to habitat disturbance: a review. International Journal of Primatology, 8(2), 157-191.

Kaplin, B. A., Munyaligoga, V., \& Moermond, T. C. (1998). The Influence of temporal changes in fruit availability on diet composition and seed handling in blue monkeys (Cercopithecus mitis doggetti). Biotropica, 30(1), 56-71.

Lahm, S. A. (1986). Diet and habitat preference of Mandrillus sphinx in Gabon: implications of foraging strategy. American Journal of Primatology, 11(1), 9-26.

639 Levene, H. (1960). Robust tests for equality of variances. In I. Olkin, S. G. Ghurye, W. 640 Hoeffding, W. G. Madow \& H. B. Mann (Eds.), Contributions to Probability and Statistics: Essays in Honor of Harold Hotelling (pp. 278-292). Stanford, USA: Stanford University Press. 
643 Litvaitis, J. A. (2000). Investigating food habits of terrestrial vertebrates. In M. C. Pearl (Ed.), 644 Research Techniques in Animal Ecology (pp. 165-190). New York, USA: Columbia $645 \quad$ University Press.

646 McGraw, W. S., Vick, A. E., \& Daegling, D. J. (2014). Dietary variation and food hardness in 647 sooty mangabeys (Cercocebus atys): implications for fallback foods and dental adaptation. 648 American Journal of Physical Anthropology, 154(3), 413-423.

649 McGrew, W. C., Marchant, L. F., \& Phillips, C. A. (2009). Standardised protocol for primate $650 \quad$ faecal analysis. Primates, 50(4), 363-366.

651 Mitani, M. (1989). Cercocebus torquatus: adaptive feeding and ranging behaviors related to 652 seasonal fluctuations of food resources in the tropical rain forest of south-western Cameroon. Primates, 30(3), 307-323.

Mori, Y., Nagamitsu, T., \& Kubo, T. (2009). Clonal growth and its effects on male and female reproductive success in Prunus ssiori (Rosaceae). Population Ecology, 51(1), 175-186.

Nakagawa, N. (1989). Bioenergetics of Japanese monkeys (Macaca fuscata) on Kinkazan Island during winter. Primates, 30(4), 441-460.

Nakashima, Y. (2015). Inventorying medium- and large-sized mammals in the African lowland rainforest using camera trapping. Tropics, 23(4), 151-164.

Newbery, D. M., Songwe, N. C., \& Chuyong, G. B. (1998). Phenology and dynamics of an African rainforest at Korup, Cameroon. In D. M. Newbery, H. H. T. Prins \& N. D. Brown (Eds.), Dynamics of tropical communities: 37th Symposium of the British Ecological Society (pp. 267-308). Oxford, UK: Blackwell Science.

Nsi Akoue, G., Mbading-Mbading, W., Willaume, E., Souza, A., Mbatchi, B., Charpentier, M. J. E., et al. (2017). Seasonal and individual predictors of diet in a free-ranging population of mandrills. Ethology, 123(9), 600-613.

O'Brien, T. G., Kinnaird, M. F., \& Wibisono, H. T. (2003). Crouching tigers, hidden prey: 
668

669

670

671

672

673

674

675

676

677

678

679

680

681

682

683

684

685

686

687

688

689

690

691

692

Sumatran tiger and prey populations in a tropical forest landscape. Animal Conservation, 6(2), 131-139.

Owens, J. R., Honarvar, S., Nessel, M., \& Hearn, G. W. (2015). From frugivore to folivore: altitudinal variations in the diet and feeding ecology of the Bioko Island drill (Mandrillus leucophaeus poensis). American Journal of Primatology, 77(12), 1263-1275.

Peres, C. A. (1994). Primate responses to phenological changes in an Amazonian terra firme forest. Biotropica, 26(1), 98-112.

R Core Team. (2017). R: a language and environment for statistical computing. R Foundation for Statistical Computing, Vienna, Austria. URL https://www.R-project.org/.

Rogers, M. E., Abernethy, K. A., Fontaine, B., Wickings, E. J., White, L. J. T., \& Tutin, C. E. G. (1996). Ten days in the life of a mandrill horde in the Lopé Reserve, Gabon. American Journal of Primatology, 40(4), 297-313.

Sato, H. (2013). Habitat shifting by the common brown lemur (Eulemur fulvus fulvus): a response to food scarcity. Primates, 54(3), 229-235.

Setchell, J. M. (2005). Do female mandrills prefer brightly colored males? International Journal of Primatology, 26(4), 715-735.

Setchell, J. M., Charpentier, M., \& Wickings, E. J. (2005). Mate guarding and paternity in mandrills: factors influencing alpha male monopoly. Animal Behaviour, 70(5), 1105-1120.

Shimodaira, H. (1998). An application of multiple comparison techniques to model selection. Annals of the Institute of Statistical Mathematics, 50(1), 1-13.

Swedell, L. (2011). African papionins: diversity of social organization and ecological flexibility. In C. J. Campbell, A. Fuentes, K. C. MacKinnon, Simon K. Bearder \& R. M. Stumpf (Eds.), Primates in Perspective (2 ed., pp. 241-277). New York, USA: Oxford Unversity Press.

Takenoshita, Y., Ando, C., Iwata, Y., Okayasu, N., Tashiro, Y., Yumoto, T., et al. (2007). Liste 
693

694

695

696

697

698

699

700

701

702

703

704

705

706

707

708

709

710

711

712

713

d'espèces de plantes vasculaire dans la partie nord du Parc National de la MoukalabaDoudou, Gabon. In J. Projet en Primatologie de l'Université de Kyoto (Ed.), Rapport de Recherches Effectuées au Parc National de Moukalaba-Doudou, Gabon: Mars 2006 Février 2007 (pp. 41-50). Kyoto, Japan.

Takenoshita, Y., Ando, C., Iwata, Y., \& Yamagiwa, J. (2008). Fruit phenology of the great ape habitat in the Moukalaba-Doudou National Park, Gabon. African Study Monographs, Suppl. 39, 23-39.

Tang, C., Huang, L., Huang, Z., Krzton, A., Lu, C., \& Zhou, Q. (2016). Forest seasonality shapes diet of limestone-living rhesus macaques at Nonggang, China. Primates, 57(1), 83-92.

Terada, S., Nackoney, J., Sakamaki, T., Mulavwa, M. N., Yumoto, T., \& Furuichi, T. (2015). Habitat use of bonobos (Pan paniscus) at Wamba: selection of vegetation types for ranging, feeding, and night-sleeping. American Journal of Primatology, 77(6), 701-713.

Terborgh, J. (1983). Five New World primates: a study in comparative ecology. Princeton, USA: Princeton University Press.

Tsuji, Y., Hanya, G., \& Grueter, C. C. (2013). Feeding strategies of primates in temperate and alpine forests: comparison of Asian macaques and colobines. Primates, 54(3), 201-215.

Tutin, C. E. G., Ham, R. M., White, L. J. T., \& Harrison, M. J. S. (1997). The primate community of the Lopé reserve, Gabon: diets, responses to fruit scarcity, and effects on biomass. American Journal of Primatology, 42(1), 1-24.

Ukizintambara, T., White, L., Abernethy, K., \& Thébaud, C. (2007). Gallery forests versus bosquets: conservation of natural fragments at Lopé National Park in central Gabon. African Journal of Ecology, 45(4), 476-482.

van Schaik, C. P., \& Pfannes, K. R. (2005). Tropical climates and phenology: a primate perspective. In D. K. Brockman \& C. P. van Schaik (Eds.), Seasonality in Primates: 
$719 \quad$ USA: Cambridge University Press.

720 Warton, D. I., \& Hui, F. K. C. (2011). The arcsine is asinine: the analysis of proportions in ecology. Ecology, 92(1), 3-10.

722

White, E. C. (2007). Ecology of Mandrillus sphinx: ranging, diet and social structure of a mandrill horde in Lopé National Park, Gabon. University of Exeter, Cornwall, UK.

724

White, E. C., Dikangadissi, J.-T., Dimoto, E., Karesh, W. B., Kock, M. D., Abiaga, N. O., et al. (2010). Home-range use by a large horde of wild Mandrillus sphinx. International Journal of Primatology, 31(4), 627-645.

White, L. J. T. (1994). Patterns of fruit-fall phenology in the Lopé Reserve, Gabon. Journal of Tropical Ecology, 10(03), 289-312.

Wild, C., Morgan, B. J., \& Dixson, A. (2005). Conservation of Drill Populations in Bakossiland, Cameroon: Historical Trends and Current Status. International Journal of Primatology, 26(4), 759-773.

732

Yamagiwa, J., Mwanza, N., Yumoto, T., \& Maruhashi, T. (1994). Seasonal change in the composition of the diet of eastern lowland gorillas. Primates, 35(1), 1-14.

734 Yumoto, T., Terakawa, M., Terada, S., Boupoya, A., \& Nzabi, T. (2015). Species composition 205-213. 